\title{
Characteristics of Chronic Rejection in Heart Transplantation: Important Elements of Pathogenesis and Future Treatments
}

\author{
Jun-ichi Suzuki, MD; Mitsuaki Isobe, MD*; Ryuichi Morishita, MD**; Ryozo Nagai, MD
}

\begin{abstract}
Although 85,000 heart transplantations have been performed worldwide, coronary allograft vasculopathy (CAV), which is a phenomenon of chronic rejection, is still a serious problem. Because CAV involves all the allograft arteries, angioplasty, stenting or bypass grafting are not practical treatment options. Therefore, CAV is the biggest long-term limitation in cardiac allograft recipients. Although the cause of CAV is mostly immunologic, nonimmune pathways also contribute to its development. Several cytokines, chemokines and adhesion molecules play a critical role in the process. Cell adhesion, migration and proliferation of bone marrow progenitor and and other cells are involved in its development. Although there is not an established clinical strategy for preventing or treating $\mathrm{CAV}$, recent investigations have provided some promising methodologies. Progress in DNA technology, such as antisense oligodeoxynucleotides (ODNs) to regulate the transcription of disease-related genes, has an important role in its therapeutic applications. Antisense ODN transfection preventing CAV in experimental cardiac allografts has been reported for the first time. The ODN strategy has not only been useful in the experimental studies, but is also a novel clinical strategy for gene therapy. The pathological and immunological characteristics of CAV and some promising methodologies for prevention of the disease are reviewed. (Circ $J$ 2010; 74: 233-239)
\end{abstract}

Key Words: Arteriosclerosis; Gene therapy; Transplantation

$\mathbf{H}$ eart transplantation is a common surgical procedure in humans; almost 85,000 operations have been performed worldwide over the past 40 years. ${ }^{1}$ However, coronary allograft vasculopathy (CAV), which is a phenomenon of chronic rejection, is still a serious problem..$^{1,2}$ Because CAV involves all the allograft arteries, angioplasty, stenting or bypass grafting are not practical treatment options. Therefore, CAV is the biggest long-term limitation in cardiac allograft recipients. CAV in cardiac allografts is especially problematic because the heart exhibits more severe disease than other transplanted organs. ${ }^{3-5}$

Several cytokines and adhesion molecules promote rejection. CAV is characterized by intimal thickening comprised of proliferative smooth muscle cells (SMCs) and extracellular matrix (ECM) with relatively intact internal and external elastic laminae. Although the cause of CAV is mostly immunologic, nonimmune pathways also contribute to its development. Inflammatory cells, such as lymphocytes, macrophages, neutrophils and eosinophils, are all variably present in evolving lesions. In the early stages, there is a subendothelial accumulation of mononuclear cells associated with markers of endothelial cell (EC) activation. Because endothelial or perivascular cellular immune injury induces persistent allograft vascular damage, inflammatory cells and activated ECs secrete growth factors to recruit and activate SMCs., ${ }^{3,6-9}$ Recently, the intimal SMCs in CAV lesions are known to derive in part from circulating host cells. Although these cells share a number of markers with medial SMCs, they are modulated cells with a proliferative and synthetic phenotype. ${ }^{3,6,10,11}$

This review article describes the characteristics of CAV, identifying the important elements of its pathogenesis in the process. Finally, a section on prevention and/or treatment of CAV is included, to represent the new approaches to future therapies.

\section{Clinical Findings of CAV}

Because transplant hearts are denervated, the clinical symptoms of ischemia are not useful for diagnosing early CAV. Coronary angiography (CAG) is still the standard methodology for the diagnosis of CAV in the clinical setting. However,

Received October 21, 2009; accepted October 29, 2009; released online December 14, 2009

Department of Advanced Clinical Science and Therapeutics, University of Tokyo, *Department of Cardiovascular Medicine, Tokyo Medical and Dental University, Tokyo, **Department of Clinical Gene Therapy, Osaka University, Suita and 'Department of Cardiovascular Medicine, University of Tokyo, Tokyo, Japan

Mailing address: Jun-ichi Suzuki, MD, Department of Advanced Clinical Science and Therapeutics, Graduate School of Medicine, University of Tokyo, 7-3-1 Hongo, Bunkyo-ku, Tokyo 113-8655, Japan. E-mail: junichisuzuki-circ@umin.ac.jp

ISSN-1346-9843 doi:10.1253/circj.CJ-09-0809

All rights are reserved to the Japanese Circulation Society. For permissions, please e-mail: cj@j-circ.or.jp 


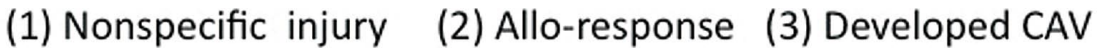

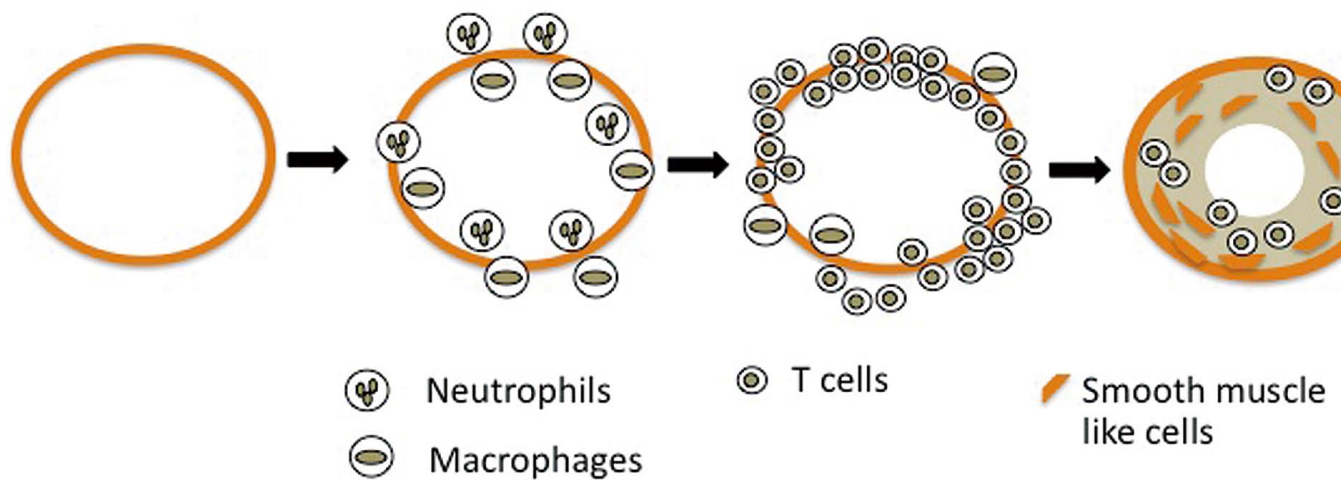

Figure 1. Three stages of coronary allograft vasculopathy (CAV) pathogenesis: nonspecific injury (Left), allo-response (Center) and developed (Right). The early nonspecific vascular injury stage has a cytokine and adhesion molecule environment. In the allo-response stage, macrophages and T lymphocytes produce additional cytokine mediators that induce endothelial and medial smooth muscle cell injury. In the developed CAV stage, the vascular wall cytokines recruit and activate smooth musclelike cells, resulting in their local proliferation and extracellular matrix production. (Modified from Annu Rev Pathol 2009; 4: 1947 with permission. ${ }^{3}$ )

CAG is relatively insensitive and underestimates the lesions because CAV involves vessels diffusely. Instead, intravascular ultrasound (IVUS) and coronary computed tomography (CT) are the preferred methods of quantitatively assessing intimal thickening. IVUS is one of the most sensitive tools for diagnosing CAV because it reveals both the actual lumen diameter and the thickness of the neointima. The examinations have proven the high frequency of CAV: $90 \%$ of patients develop CAV within 10 years. Of note, CAV development does not correlate with either the number of episodes or the severity of cellular rejection, and vascular lesions occur despite adequate immunosuppression to prevent acute rejection. ${ }^{4,12}$ However, the IVUS is invasive and thus associated with the risk of complications, whereas contrast CT can provide a comprehensive and noninvasive evaluation of CAV. It may be useful as a single noninvasive procedure, not only for CAV evaluation but also for assessment of allograft function and other complications. ${ }^{13}$

\section{Pathology of CAV}

Pathologically, CAV involves the entire length of the transplanted arterial vasculature. CAV is characterized by concentric intimal thickening comprised of SMCs and ECM, with relatively intact internal and external elastic laminae. The vascular media and adventitia are relatively unaffected. Inflammatory cells are variably present in evolving lesions, but calcification and atheroma formation are also uncommon. ${ }^{3}$

Based on the registry of the International Society for Heart and Lung Transplantation 2009, risk factors for CAV within 8 years are: donor history of hypertension; induction therapy with interleukin (IL)-2 antagonist or OKT3; pretransplant diagnosis of coronary artery disease; increasing number of HLA-DR mismatches etc. ${ }^{1}$ Other risk factors include obesity, diabetes, hyperlipidemia, viral infection and hyperhomocysteinemia. ${ }^{3}$

Allografts are subject to multiple injuries, by immune and nonimmune factors. Although many factors contribute to
CAV development, any of the various injuries can independently induce CAV. Immune injury is known to play a critical role in CAV pathogenesis. Although cellular immune responses are central in CAV development, humoral injury is also recognized as a critical component. The predominant effector cells are macrophages; they secrete proinflammatory cytokines that influence the proliferation of smooth musclelike cells (SMLCs) and fibroblasts and the ECM synthesis that results in CAV formation (Figure 1). Recipient T cells require 2 signals to be activated: 1 signal involves host T-cell receptor interaction with the donor major histocompatibility complex (MHC) and the other signal involves ligation of costimulatory molecules. The nature and efficiency of both signals affect the development of CAV. ${ }^{14,15}$

Nonimmune risk factors, including ischemia, diabetes and hypertension, correlate with the intimal thickening of CAV. Periods of ischemia are significantly important for promoting CAV; the effects are attributable to ischemic ECs, which increases local platelet accumulation. Ischemic injury to ECs can also increase MHC and adhesion-molecule expression. ${ }^{16,17}$ Cytomegalovirus is known to be associated with an increased incidence of CAV, which in turn is associated with enhancement of multiple genes associated with wound repair and angiogenesis. ${ }^{18,19}$

\section{Costimulatory Signals}

Costimulatory signals are important for stimulation of T cells and inflammatory cell recruitment into the allograft. ${ }^{20}$ It has been reported that CAV correlates with expression of adhesion molecules, including intracellular adhesion molecule (ICAM)-1, vascular cell adhesion molecule-1, and the E- and P-selectins. ${ }^{21,22}$ Besides facilitating EC interactions, lymphocyte integrins can also act as costimulatory molecules during antigen presentation. Although blockade of ICAM-1 and leukocyte function associated antigen-1 interactions induces allograft tolerance, ${ }^{23}$ the absence of this signal suppresses but does not completely prevent CAV development. ${ }^{24}$ It has been reported that CTLA-4 blockade of B7-CD28 interactions attenuated CAV. ${ }^{25}$ The inducible costimulator (ICOS) mole- 


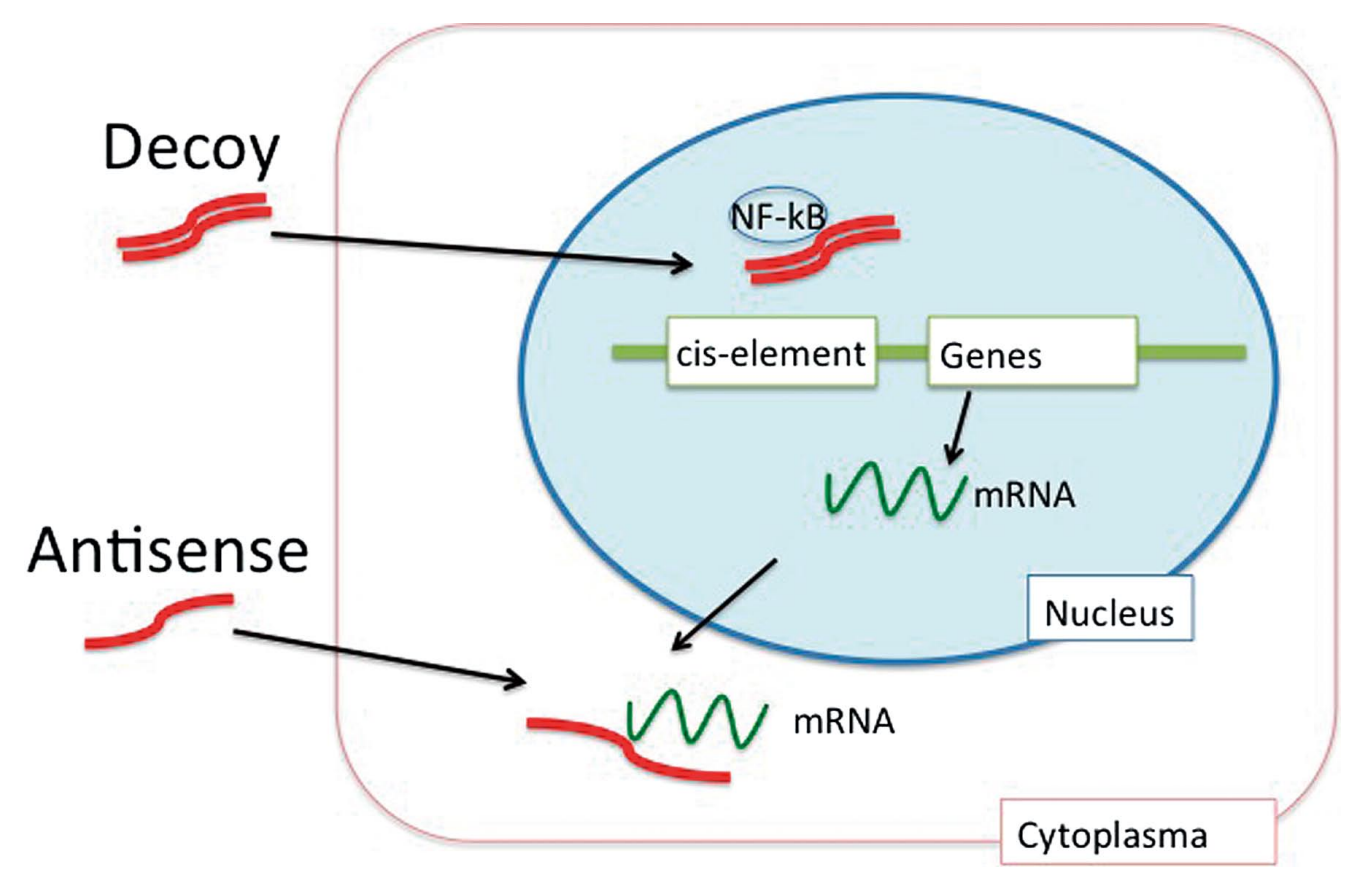

Figure 2. The targeted molecular pathways and how the treatments fit into the immunopathophysiology of coronary allograft vasculopathy. (Modified from Jpn Circ J 1998; 62: 315-327 with permission. ${ }^{62}$ ) NF- $\kappa$ B, nuclear factor- $\kappa$ B.

cule on $\mathrm{T}$ cells can also influence CAV development by directly interacting with the ICOS-ligand on medial SMCs activated by IL-1 $\beta .{ }^{26,27} \mathrm{We}$ also found that blockade of selectin, ${ }^{28}$ LIGHT, ${ }^{29}$ and $4-1 \mathrm{BB}^{30}$ attenuated CAV, whereas PD blockade accelerated its development. ${ }^{31}$ Because each costimulatory signal has a different effect on CAV development, investigation of anti-costimulatory therapy should evaluate different organs and conditions.

\section{Cytokines}

Cytokines mediate local and systemic immune responses. Interferon (IFN)- $\gamma$ is the most important player because it activates macrophages, augments inflammatory cell recruitment and amplifies immune responses. ${ }^{32}$ Despite ongoing acute rejection, the absence of IFN- $\gamma$ abrogates CAV..$^{33}$ In association with IFN- $\gamma$-induced cytokines, the IFN- $\gamma$ and IL-12 relationship is a critical element in CAV pathogenesis because medial SMCs synthesize IFN- $\gamma$ following stimulation by IL-12 and IL-18. ${ }^{34}$ Although IFN- $\gamma$ blocks medial SMC proliferation in vitro, IFN- $\gamma$ directly induces intimal hyperplasia in the absence of inflammatory cells. ${ }^{35}$ Other proinflammatory cytokines downstream of IFN- $\gamma$ also play an important role. We reported that with both tumor necrosis factor (TNF) receptor-1 and -2 deficiencies CAV did not develop, despite normal host inflammatory cell IFN- $\gamma$ production. ${ }^{36}$ Because host TNF-receptor deficiency did not reduce $\mathrm{CAV}$, the effect was not attributable to TNF signaling on host inflammatory cells.

\section{Chemokines}

Chemokines are known to recruit and activate inflammatory cells. They are classified into 4 groups: CC, CXC, XC, and $\mathrm{CX} 3 \mathrm{C}$. The roles of these molecules in acute rejection and CAV have been investigated. ${ }^{37}$ RANTES is a well-charac- terized CC chemokine implicated in the pathogenesis of both atherosclerosis and CAV. ${ }^{38}$ Other chemokines, the IFN- $\gamma$ inducible IP10, Mig, and I-TAC, are critical for their strong association with CAV ${ }^{39,40}$ Moreover, targeted deletion of CCR1 reduces both acute rejection and the development of CAV. ${ }^{41}$

\section{Sources of Cells in CAV}

Although SMLCs are similar in appearance to medial SMCs, they are phenotypically modulated cells with different genetic expression profiles. We have shown that medial SMC have a contractile function, whereas SMLC exhibit a more embryonic, synthetic phenotype. ${ }^{10}$ Previously, CAV intimal cells were assumed to derive from the migration and proliferation of donor medial SMCs. However, several groups have shown that intimal SMLCs can also be of host origin. In animal models, the proportion of host origin SMLCs in intimal lesions exceeds $90 \% . .^{42-44}$ However, in gender-mismatched cardiac allografts, Y-chromosome in situ hybridization identified only 3-15\% host-derived intimal SMLCs. ${ }^{45,46}$ These results demonstrate that both host bone marrow and non-bone marrow precursors contribute to CAV development. Therefore, therapies against CAV may need to account for different cell origins, routes of recruitment, and differentiation pathways.

\section{Prevention and Treatments}

\section{Clinically Applicable Treatments}

Studies have shown that HMG-CoA reductase inhibitors (statins) play an important role in the prevention of CAV. The effects of statins are mediated by multiple immunogenic effects. Simvastatin reduces proinflammatory cytokine activity, improves coronary endothelial function and increases the area of the coronary artery lumen. ${ }^{47}$ Calcium-channel blockers 

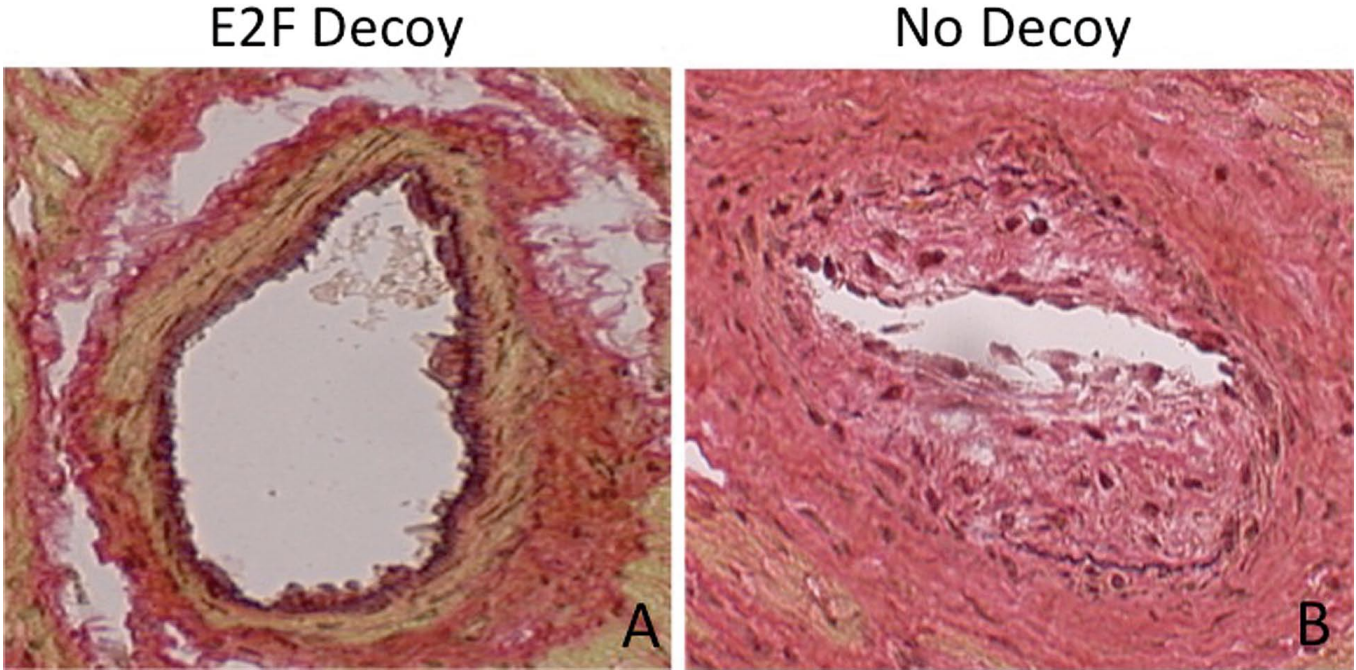

Figure 3. Representative findings in allograft coronary arteries. (A) Effects of E2F decoy compared with controls (B) on the intimal hyperplasia that defines coronary allograft vasculopathy. (Modified from Circ Res 2000; 87: 1063-1068 with permission. ${ }^{71}$ )

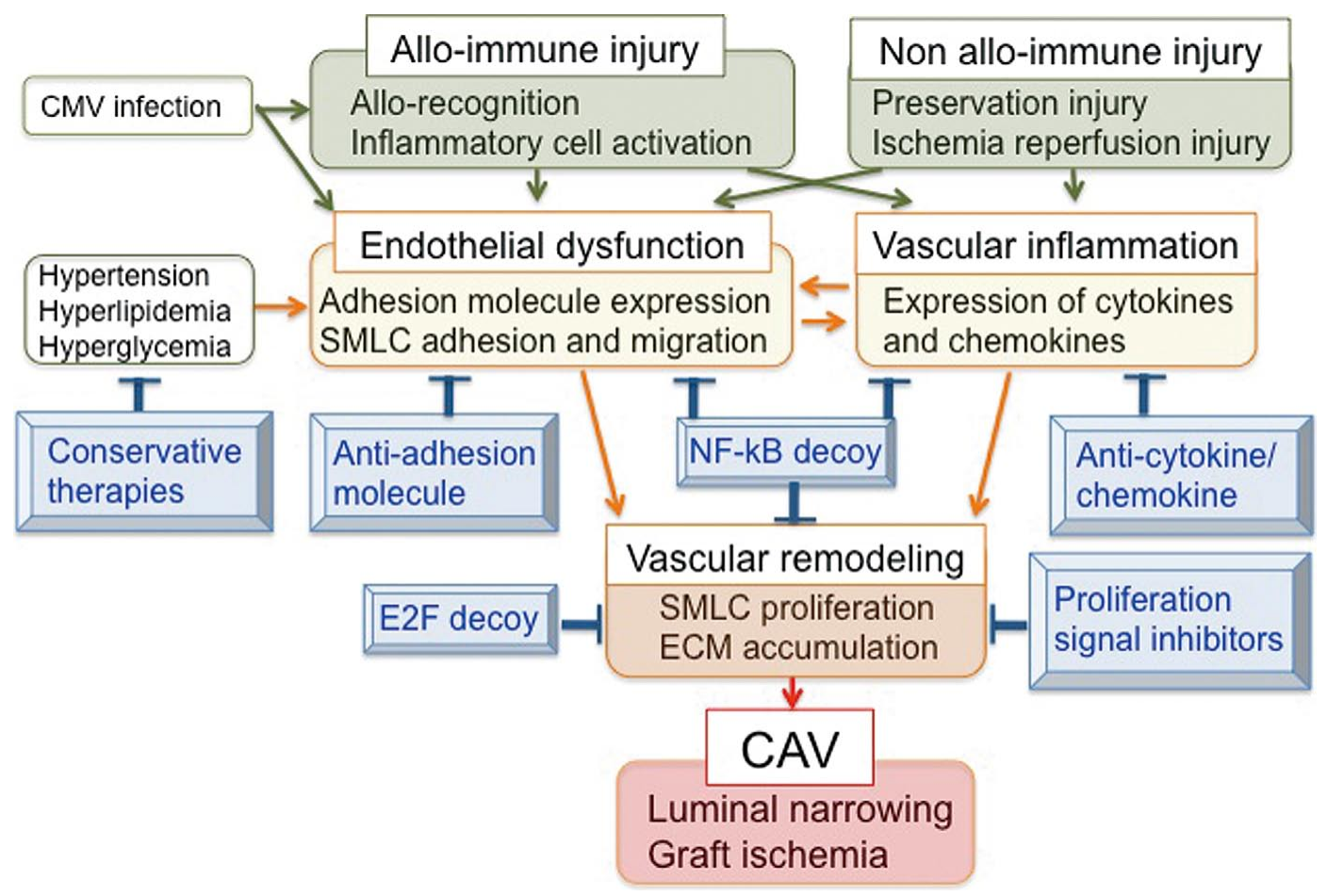

Figure 4. Summary of the pathological and immunological characteristics of CAV (black) and some promising methodologies for prevention (blue). CAV, coronary allograft vasculopathy; CMV, cytomegalovirus; ECM, extracellular matrix; NF- $\kappa \mathrm{B}$, nuclear factor- $\kappa \mathrm{B}$; SMLC, smooth muscle-like cell.

are also known to delay the progression of CAV and enhance coronary vasodilation. ${ }^{48}$ Angiotensin-converting enzyme (ACE) inhibitors partially improve allograft endothelial dysfunction, oxidative stress and endothelin activation. They are also associated with plaque regression and improved graft survival. ${ }^{49,50}$ Recently, a synergistic beneficial effect of a calcium-channel blocker and an ACE inhibitor on the development of CAV was described. ${ }^{51}$ Other drugs, such as vitamins and flavonoids, might have the potential to restore allograft endothelial function. ${ }^{52,53}$ 
Cyclosporin A (CyA) significantly suppresses acute cardiac allograft rejection, but has not been effective in preventing CAV. ${ }^{54}$ Although tacrolimus provides superior prevention of acute rejection compared with CyA, CAV development was similar between CyA- and tacrolimus-treated groups. ${ }^{55}$ It has been reported that mycophenolate mofetil significantly decreased both first-year maximal intimal thickness ${ }^{56}$ and the incidence of CAV. ${ }^{57}$ Recently, proliferation signal inhibitors were shown to have significant effects on preventing CAV. Sirolimus has delayed the progression of CAV in some clinical trials. ${ }^{58,59}$ Another proliferation signal inhibitor, everolimus, also prevented CAV development. ${ }^{60}$ However, as there is not yet a report of the long-term effect of proliferation signal inhibitors in suppressing CAV, further observation studies are needed.

\section{Treatments Under Investigation}

Possible targets to prevent CAV are chemokines, cytokines, costimulatory signals, cell proliferation and apoptosis. It has been reported that the induction of transient mixed hematopoietic chimerism leads to long-term heart allograft survival and CAV did not develop in MHC disparate monkeys without chronic immunosuppression. ${ }^{61}$ However, tolerance induction and systemic immune modulation may cause adverse effects; limited treatment of transplant organs is ideal for the long-term survival of recipients. Thus, we have investigated the effects of a limited gene transfer system to allografts for the prevention of CAV. ${ }^{62}$

Recent progress in DNA technology, such as antisense oligodeoxynucleotides (ODNs) to regulate the transcription of disease-related genes, has shown that the technology will have an important role in therapeutic applications ${ }^{63}$ (Figure 2). In our study, we first selected antisense cdk2 kinase ODN, because the enzyme plays an important role in cell transition through the G1/S phase. ${ }^{64} \mathrm{We}$ then showed that treatment with antisense cdk2 kinase ODN significantly reduced CAV. ${ }^{65}$ Next, we transfected the allografts with antisense PCNA ODN, because PCNA plays an essential role in cell transition through both the G1/S and G2/M phases. ${ }^{66} \mathrm{We}$ observed limited neointimal formation in antisense PCNA ODN-transfected allografts. ${ }^{67} \mathrm{We}$ also targeted apoptosis because it is a prominent feature of atherosclerosis. ${ }^{68}$ We clarified that antisense $b c l-x$ ODN suppresses CAV with increased TUNELpositive cells. ${ }^{69}$

Transfection of cis-element double-stranded DNA, termed "decoy", has been reported as a useful method for gene therapy. The transcription factor E2F regulates multiple cell-cycle regulatory genes, which are critical to the process of cell growth and proliferation. ${ }^{70}$ To clarify the effects of E2F decoy ODN on CAV, we used both murine and monkey cardiac transplant models, which showed that E2F decoy ODN transfer into the allografts specifically abolishes E2F activity and inhibites $\mathrm{CAV}^{71}$ (Figure 3). Another critical transcription factor, nuclear factor- $\kappa \mathrm{B}$ (NF- $\kappa \mathrm{B})$, plays a pivotal role in the coordinated transcription of multiple inflammatory genes. ${ }^{72}$ We demonstrated that NF- $\kappa \mathrm{B}$ decoy ODN inhibits CAV effectively and of note, the NF- $\kappa$ B decoy ODN attenuated both chronic and acute rejection. ${ }^{73}$

Although the decoy ODN strategies have not yet been used in clinical transplantation, the effects have been investigated in coronary bypass grafting and coronary angioplasty in the clinical setting. It was reported that ex vivo E2F decoy ODN transfection in vascular grafts suppresses neointimal hyperplasia after cardiac bypass surgery..$^{74,75} \mathrm{We}$ also tried NF- $\kappa \mathrm{B}$ decoy ODN transfection of the site in coronary arteries after stent implantation in humans and the results demonstrated that the strategy is clinically promising. ${ }^{76-78}$ Thus, further studies should be conducted in other transplant models to explore the clinical utility of this technology for prevention of CAV.

\section{Summary}

Although improved surgical techniques have resulted in excellent graft function, ${ }^{79} \mathrm{CAV}$ remains a problem to be resolved by treatment. Because heart transplantation in Japan has been very limited by a severe shortage of donors, ${ }^{80}$ preventing CAV is critical for the prognosis of recipients. We have described the pathological and immunological characteristics of CAV. Several cytokines, chemokines and adhesion molecules play a critical role in the process. Cell adhesion, migration and proliferation of bone marrow and other cells are involved in its development. Although there is not yet an established clinical strategy for preventing or treating CAV, recent investigations have provided some promising methodologies (Figure 4). Therefore, further studies are needed to clarify the clinical prevention of CAV.

\section{Acknowledgments}

We thank Professors Peter Libby and Richard N. Mitchell for their encouragement and mentorship. We also thank Mr Masahito Ogawa, Ms Noriko Tamura and Ms Yasuko Matsuda for their excellent assistance.

\section{References}

1. Taylor DO, Stehlik J, Edwards LB, Aurora P, Christie JD, Dobbels $\mathrm{F}$, et al. Registry of the international society for heart and lung transplantation: Twenty-sixth official adult heart transplant report2009. J Heart Lung Transplant 2009; 28: 1007-1022.

2. Vega JD, Moore J, Murray S, Chen JM, Johnson MR, Dyke DB. Heart transplantation in the United States, 1998-2007. Am J Transplant 2009; 9: 932-941.

3. Mitchell RN. Graft vascular disease: Immune response meets the vessel wall. Annu Rev Pathol 2009; 4: 19-47.

4. Schmauss D, Weis M. Cardiac allograft vasculopathy: Recent developments. Circulation 2008; 117: 2131-2141.

5. Ramzy D, Rao V, Brahm J, Miriuka S, Delgado D, Ross HJ. Cardiac allograft vasculopathy: A review. Can J Surg 2005; 48: 319327.

6. Mitchell R, Libby P. Vascular remodeling in transplant vasculopathy. Circ Res 2007; 100: 967-978.

7. Libby P, Pober J. Chronic rejection. Immunity 2001; 14: 387-397.

8. Furukawa Y, Libby P, Stinn J, Becker G, Mitchell R. Cold ischemia enhances cytokine/cell adhesion molecule expression and induces graft arterial disease in isografts, but does not accentuate alloimmune responses of nonimmunosuppressed hosts. Am J Pathol 2002; 160: $1077-1087$.

9. Dhaliwal A, Thohan V. Cardiac allograft vasculopathy: The Achilles heel of long-term survival after cardiac transplantation. Curr Atheroscler Rep 2006; 8: 119-130.

10. Suzuki J, Isobe M, Aikawa M, Kawauchi M, Shiojima I, Kobayashi $\mathrm{N}$, et al. Nonmuscle and smooth muscle myosin heavy chain expression in rejected cardiac allografts: A study in rat and monkey models. Circulation 1996; 94: 1118-1124.

11. Shah R, Mitchell $\mathrm{R}$. The role of stem cells in the response to myocardial and vascular wall injury. Cardiovasc Pathol 2005; 14: 225 231.

12. Tuzcu E, Kapadia S, Sachar R, Ziada K, Crowe T, Feng J, et al. Intravascular ultrasound evidence of angiographically silent progression in coronary atherosclerosis predicts long-term morbidity and mortality after cardiac transplantation. J Am Coll Cardiol 2005; 45: $1538-1542$.

13. Bogot NR, Durst R, Shaham D, Admon D. Cardiac CT of the transplanted heart: Indications, technique, appearance, and complications. Radiographics 2007; 27: 1297-1309.

14. Michaels P, Espejo M, Kobashigawa J, Alejos J, Burch C, Takemoto $\mathrm{S}$, et al. Humoral rejection in cardiac transplantation: Risk factors, hemodynamic consequences and relationship to transplant coronary artery disease. J Heart Lung Transplant 2003; 22: 
$58-69$.

15. Wehner J, Morrell C, Reynolds T, Rodriguez E, Baldwin W. Antibody and complement in transplant vasculopathy. Circ Res 2007; 100: $191-203$.

16. Caforio A, Tona F, Fortina A, Angelini A, Piaserico S, Gambino $\mathrm{A}$, et al. Immune and nonimmune predictors of cardiac allograft vasculopathy onset and severity: Multivariate risk factor analysis and role of immunosuppression. Am J Transplant 2004; 4: 962 970.

17. el-Sawy T, Fahmy N, Fairchild R. Chemokines: Directing leukocyte infiltration into allografts. Curr Opin Immunol 2002; 14: $562-$ 568.

18. Valantine $\mathrm{H}$. The role of viruses in cardiac allograft vasculopathy. Am J Transplant 2004; 4: 169-177.

19. Streblow D, Kreklywich C, Andoh T, Moses A, Dumortier J, Smith $\mathrm{PP}$, et al. The role of angiogenic and wound repair factors during $\mathrm{CMV}$-accelerated transplant vascular sclerosis in rat cardiac transplants. Am J Transplant 2008; 8: 277-287.

20. Isobe M, Kosuge H, Suzuki J. T cell costimulation in the development of cardiac allograft vasculopathy: Potential targets for therapeutic interventions. Arterioscler Thromb Vasc Biol 2006; 26: $1447-1456$.

21. Denton M, Davis S, Baum M, Melter M, Reinders M, Exeni A, et al. The role of the graft endothelium in transplant rejection: Evidence that endothelial activation may serve as a clinical marker for the development of chronic rejection. Pediatr Transplant 2000; 4: $252-260$.

22. Dietrich H, Hu Y, Zou Y, Dirnhofer S, Kleindienst R, Wick G, et al. Mouse model of transplant arteriosclerosis: Role of intercellular adhesion molecule-1. Arterioscler Thromb Vasc Biol 2000; 20: $343-352$.

23. Isobe M, Yagita H, Okumura K, Ihara A. Specific acceptance of cardiac allograft after treatment with antibodies to ICAM-1 and LFA-1. Science 1992; 255: 1125-1127.

24. Suzuki J, Isobe M, Yamazaki S, Sekiguchi M. Inhibition of accelerated coronary atherosclerosis with short-term blockade of intercellular adhesion molecule-1 and lymphocyte function-associated antigen-1 in a heterotopic murine model of heart transplantation. J Heart Lung Transplant 1997; 16: 1141 - 1148.

25. Furukawa Y, Mandelbrot D, Libby P, Sharpe A, Mitchell R. Association of B7-1 costimulation with the development of graft arterial disease: Studies using mice lacking B7-1, B7-2, or B7-1/B7-2. Am J Pathol 2000; 157: 473-484.

26. Kosuge H, Suzuki J, Gotoh R, Koga N, Ito H, Isobe M, et al. The induction of immunological tolerance to cardiac allograft by simultaneous blockade of inducible co-stimulator (ICOS) and CTLA4 pathway. Transplantation 2003; 75: 1374-1379.

27. Kosuge H, Suzuki J, Haraguchi G, Koga N, Maejima Y, Inobe M, et al. Critical role of inducible costimulator signaling in the development of arteriosclerosis. Arterioscler Thromb Vasc Biol 2006; 26: $2660-2665$.

28. Yamazaki S, Isobe M, Suzuki J, Tojo S, Horie S, Okubo Y, et al. Role of selectin-dependent adhesion in cardiac allograft rejection. J Heart Lung Transplant 1998; 17: 1007-1016.

29. Kosuge H, Suzuki J, Kakuta T, Haraguchi G, Koga N, Futamatsu $\mathrm{H}$, et al. Attenuation of graft arterial disease by manipulation of the LIGHT pathway. Arterioscler Thromb Vasc Biol 2004; 24: 14091415.

30. Saiki H, Suzuki J, Kosuge H, Haraguchi G, Haga T, Maejima Y, et al. Blockade of the 4-1BB pathway attenuates graft arterial disease in cardiac allografts. Int Heart J 2008; 49: 105-118.

31. Koga N, Suzuki J, Kosuge H, Haraguchi G, Onai Y, Futamatsu H, et al. The blockade of the interaction between PD-1 and PD-L1 accelerates graft arterial disease in cardiac allografts. Arterioscler Thromb Vasc Biol 2004; 24: 2057-2062.

32. Tellides G, Pober J. Interferon- $\gamma$ axis in graft arteriosclerosis. Circ Res 2007; 100: 622-632.

33. Nagano H, Mitchell R, Taylor M, Hasegawa S, Tilney N, Libby P. Interferon- $\gamma$ deficiency prevents coronary arteriosclerosis but not myocardial rejection in transplanted mouse hearts. J Clin Invest 1997; 100: $550-557$

34. Gerdes N, Sukhova G, Libby P, Reynolds R, Young J, Schönbeck U. Expression of interleukin-18 and functional IL-18 receptor on vascular endothelial cells, smooth muscle cells, and macrophages: Implication for atherogenesis. J Exp Med 2002; 195: 245-257.

35. Tellides G, Tereb D, Kirkiles-Smith N, Kim R, Wilson JH, Schechner JS, et al. Interferon- $\gamma$ elicits arteriosclerosis in the absence of leukocytes. Nature 2000; 403: 207-211.

36. Suzuki J, Cole S, Batirel S, Kosuge H, Shimizu K, Isobe M, et al. Tumor necrosis factor receptor- 1 and -2 double deficiency reduces graft arterial disease in murine cardiac allografts. Am J Transplant 2003; 3: 968-976.

37. Nelson P, Krensky A. Chemokines, chemokine receptors, and allograft rejection. Immunity 2001; 14: 377-386.

38. von Hundelshausen P, Weber K, Huo Y, Proudfoot A, Nelson P, Ley K, et al. RANTES deposition by platelets triggers monocyte arrest on inflamed and atherosclerotic endothelium. Circulation 2001; 103: $1772-1777$

39. Zhao D, Hu Y, Miller G, Luster A, Mitchell R, Libby P. Differential expression of the IFN- $\gamma$-inducible CXCR3-binding chemokines, IFN-inducible protein 10, monokine induced by IFN, and IFNinducible $\mathrm{T}$ cell $\alpha$ chemoattractant in human cardiac allografts: Association with cardiac allograft vasculopathy and acute rejection. J Immunol 2002; 169: 1556-1560.

40. van Loosdregt $\mathrm{J}$, van Oosterhout $\mathrm{M}$, Bruggink A, van Wichen D, van Kuik J, de Koning E, et al. The chemokine and chemokine receptor profile of infiltrating cells in the wall of arteries with cardiac allograft vasculopathy is indicative of a memory T-helper 1 response. Circulation 2006; 114: 1599-1607.

41. Gao W, Topham P, King J, Smiley S, Csizmadia V, Lu B, et al. Targeting of the chemokine receptor CCR1 suppresses development of acute and chronic cardiac allograft rejection. J Clin Invest 2000; 105: $35-44$

42. Shimizu K, Mitchell R. Stem cell origins of intimal cells in graft arterial disease. Curr Atheroscler Rep 2003; 5: 230-237.

43. Hillebrands J, Klatter F, Rozing J. Origin of vascular smooth muscle cells and the role of circulating stem cells in transplant arteriosclerosis. Arterioscler Thromb Vasc Biol 2003; 23: 380-387.

44. Hillebrands J, Klatter F, van den Hurk BM, Popa E, Nieuwenhuis $\mathrm{P}$, Rozing J. Origin of neointimal endothelium and $\alpha$-actin-positive smooth muscle cells in transplant arteriosclerosis. J Clin Invest 2001; 107: $1411-1422$.

45. Glaser R, Lu M, Narula N, Epstein J. Smooth muscle cells, but not myocytes, of host origin in transplanted human hearts. Circulation 2002; 106: $17-19$

46. Minami E, Laflamme M, Saffitz J, Murry C. Extracardiac progenitor cells repopulate most major cell types in the transplanted human heart. Circulation 2005; 112: 2951-2958.

47. Wenke K, Meiser B, Thiery J, Nagel D, von Scheidt W, Krobot K, et al. Simvastatin initiated early after heart transplantation: 8-year prospective experience. Circulation 2003; 107: 93-97.

48. Schroeder JS, Gao SZ, Alderman EL, Hunt SA, Johnstone I, Boothroyd DB, et al. A preliminary study of diltiazem in the prevention of coronary artery disease in heart-transplant recipients. N Engl J Med 1993; 328: 164-170.

49. Steinhauff S, Pehlivanli S, Bakovic-Alt R, Meiser BM, Becker BF, von Scheidt W, et al. Beneficial effects of quinaprilat on coronary vasomotor function, endothelial oxidative stress, and endothelin activation after human heart transplantation. Transplantation 2004; 77: $1859-1865$.

50. Bae JH, Rihal CS, Edwards BS, Kushwaha SS, Mathew V, Prasad A, et al. Association of angiotensin-converting enzyme inhibitors and serum lipids with plaque regression in cardiac allograft vasculopathy. Transplantation 2006; 82: 1108-1111.

51. Erinc K, Yamani MH, Starling RC, Crowe T, Hobbs R, BottSilverman C, et al. The effect of combined angiotensin-converting enzyme inhibition and calcium antagonism on allograft coronary vasculopathy validated by intravascular ultrasound. J Heart Lung Transplant 2005; 24: $1033-1038$.

52. Fang JC, Kinlay S, Beltrame J, Hikiti H, Wainstein M, Behrendt $\mathrm{D}$, et al. Effect of vitamins $\mathrm{C}$ and $\mathrm{E}$ on progression of transplantassociated arteriosclerosis: A randomised trial. Lancet 2002; 359: $1108-1113$.

53. Iwanaga K, Hasegawa T, Hultquist DE, Harada H, Yoshikawa Y, Yanamadala S, et al. Riboflavin-mediated reduction of oxidant injury, rejection, and vasculopathy after cardiac allotransplantation. Transplantation 2007; 83: 747-753.

54. Segovia J, Gomez-Bueno M, Alonso-Pulpon L. Treatment of allograft vasculopathy in heart transplantation. Expert Opin Pharmacother 2006; 7: 2369-2383.

55. Kobashigawa JA, Patel J, Furukawa H, Moriguchi JD, Yeatman L, Takemoto S, et al. Five-year results of a randomized, single-center study of tacrolimus vs microemulsion cyclosporine in heart transplant patients. J Heart Lung Transplant 2006; 25: 434-439.

56. Kobashigawa JA, Tobis JM, Mentzer RM, Valantine HA, Bourge RC, Mehra MR, et al. Mycophenolate mofetil reduces intimal thickness by intravascular ultrasound after heart transplant: Reanalysis of the multicenter trial. Am J Transplant 2006; 6: 993-997.

57. Kaczmarek I, Ertl B, Schmauss D, Sadoni S, Knez A, Daebritz S, et al. Preventing cardiac allograft vasculopathy: Long-term bene- 
ficial effects of mycophenolate mofetil. J Heart Lung Transplant 2006; 25: 550-556.

58. Mancini D, Pinney S, Burkhoff D, LaManca J, Itescu S, Burke E, et al. Use of rapamycin slows progression of cardiac transplantation vasculopathy. Circulation 2003; 108: $48-53$.

59. Keogh A, Richardson M, Ruygrok P, Spratt P, Galbraith A, O'Driscoll G, et al. Sirolimus in de novo heart transplant recipients reduces acute rejection and prevents coronary artery disease at 2 years: A randomized clinical trial. Circulation 2004; 110: 2694 2700.

60. Eisen HJ, Tuzcu EM, Dorent R, Kobashigawa J, Mancini D, Valantine-von Kaeppler HA, et al. Everolimus for the prevention of allograft rejection and vasculopathy in cardiac-transplant recipients. N Engl J Med 2003; 349: 847-858.

61. Kawai T, Cosimi AB, Wee SL, Houser S, Andrews D, Sogawa H, et al. Effect of mixed hematopoietic chimerism on cardiac allograft survival in cynomolgus monkeys. Transplantation 2002; 73: $1757-$ 1764.

62. Isobe M, Suzuki J. New approaches to the management of acute and chronic cardiac allograft rejection. Jpn Circ J 1998; 62: 315-327.

63. Morishita R. Perspective in progress of cardiovascular gene therapy. J Pharmacol Sci 2004; 95: 1-8.

64. Tsai LH, Harlow E, Meyerson M. Isolation of the human cdk2 gene that encodes the cycline A and adenovirus E1A associated p33 kinase. Nature 1991; 353: 174-177.

65. Suzuki J, Isobe M, Morishita R, Aoki M, Horie S, Okubo Y, et al. Prevention of graft coronary arteriosclerosis by antisense cdk2 kinase oligonucleotide. Nat Med 1997; 3: 900-903.

66. Morishita R, Gibbons GH, Ellison KE, Nakajima M, Zhang L, Kaneda Y, et al. Single intraluminal delivery of antisense cdc 2 kinase and proliferating-cell nuclear antigen oligonucleotides results in chronic inhibition of neointimal hyperplasia. Proc Natl Acad Sci USA 1993; 90: 8474-8478.

67. Suzuki J, Isobe M, Morishita R, Nishikawa T, Amano J, Kaneda Y. Prevention of cardiac allograft arteriosclerosis using antisense proliferating-cell nuclear antigen oligonucletide. Transplantation 2000; 70: $398-400$.

68. Geng YJ, Libby P. Evidence for apoptosis in advanced human atheroma: Colocalization with interleukin-1 beta-converting enzyme. Am J Pathol 1995; 147: 251-266.

69. Suzuki J, Isobe M, Morishita R, Nishikawa T, Amano J, Kaneda Y. Antisense bcl-x oligonucleotide induces apoptosis and prevents arterial neointimal formation in murine cardiac allografts. Cardiovasc Res 2000; 45: 783-787.

70. Morishita R, Gibbons GH, Horiuchi M, Ellison KE, Nakajima M, Chang $\mathrm{L}$, et al. A gene strategy using a transcription factor decoy of the E2F binding site inhibits smooth muscle proliferation in vivo. Proc Natl Acad Sci USA 1995; 92: 5855-5859.

71. Kawauchi M, Suzuki J, Morishita R, Wada Y, Izawa A, Tomita N, et al. Gene therapy for attenuating cardiac allograft arteriopathy using ex vivo E2F decoy transfection by HVJ-AVE-liposome method in mice and nonhuman primates. Circ Res 2000; 87: $1063-$ 1068.

72. Barnes PJ, Karin M. Nuclear factor-kappaB: A pivotal transcription factor in chronic inflammatory diseases. N Engl J Med 1997; 336: $1066-1071$.

73. Suzuki J, Morishita R, Amano J, Kaneda Y, Isobe M. Decoy against nuclear factor-kappa B attenuates myocardial cell infiltration and arterial neointimal formation in murine cardiac allografts. Gene Ther 2000; 7: 1847-1852.

74. Mann MJ, Whittemore AD, Donaldson MC, Belkin M, Conte MS, Polak JF, et al. Ex-vivo gene therapy of human vascular bypass grafts with E2F decoy: The PREVENT single-centre, randomised, controlled trial. Lancet 1999; 354: 1493-1498.

75. Alexander JH, Hafley G, Harrington RA, Peterson ED, Ferguson TB Jr, Lorenz TJ, et al. Efficacy and safety of edifoligide, an E2F transcription factor decoy, for prevention of vein graft failure following coronary artery bypass graft surgery: PREVENT IV: A randomized controlled trial. JAMA 2005; 294: 2446-2454.

76. Suzuki J, Ito H, Gotoh R, Morishita R, Egashira K, Isobe M. Initial clinical cases using an NF- $\kappa \mathrm{B}$ decoy at the site of the coronary stenting for prevention of restenosis. Circ J 2004; 68: 270-271.

77. Egashira K, Suzuki J, Ito H, Aoki M, Isobe M, Morishita R for INDOR Study Group. Long-term follow up of initial clinical cases with NF- $\kappa$ B decoy oligodeoxynucleotide transfection at the site of the coronary stenting. J Gene Med 2008; 10: 805-809.

78. Suzuki J, Tezuka D, Morishita R, Isobe M. An initial case of suppressed restenosis with NF- $\kappa \mathrm{B}$ decoy transfection after PCI. J Gene Med 2009; 11: 89-91.

79. Kitamura S, Nakatani T, Kato T, Yanase M, Kobayashi J, Nakajima $\mathrm{H}$, et al. Hemodynamic and echocardiographic evaluation of orthotopic heart transplantation with the modified bicaval anastomosis technique. Circ J 2009; 73: 1235-1239.

80. Nakatani T. Heart transplantation. Circ J 2009; 73: A-55-A-60. 